https://doi.org/10.5817/OS2020-3-8

\title{
Osip Mandel'štam aus der Sicht des Performativen
}

БОГЕН, С.: «Блаженное бессмысленное слово»: к перфомансу несказанного в поэзии позднего Мандельштама. Berlin: Peter Lang (= Slavische Literaturen 51) 2018, 207 S. (Abb.). ISBN 978-3-631-77574-5.

Die wissenschaftliche Auseinandersetzung mit dem lyrischen Werk Osip Mandel'štams sowohl in Russland selbst als auch außerhalb davon wird seit Jahrzehnten von dem Bestreben dominiert, den vielfach verrätselten Texten des Autors immer neue Subtexte abzuringen, die Mandel'štam entweder als bewusst gesetzte Allusionen in seine Gedichte eingebaut hat oder die direkt über die sprachlichen Verweiszusammenhänge aktualisiert werden. Von daher eröffnet die vorliegende Untersuchung in ihrer Fokussierung auf die im Titel des Bandes angesprochene Funktion des Performativen einen deutlich markierten Kontrapunkt. Dabei lässt Bogen bedauerlicherweise rezentere theoretische Ansätze zu dieser Frage weitestgehend außer Acht und widmet sich im ersten, einleitenden Teil ihrer Studie vielmehr Fragen der Sprachphilosophie und hier wiederum bevorzugt der Problematik des (Un-)Nennbaren. Diese Punkte werden in teilweise recht knapp und kursorisch gehaltenen Unterabschnitten in der Auseinandersetzung mit Mandel'štams essayistischem Werk und den daraus resultierenden Bezügen zu Juden- und Christentum, aber auch zu zentralen philosophischen europäischen Verweisgrößen der Jahrhundertwende wie Friedrich Nietzsche, Henri Bergson oder Pavel Florenskij und zu dessen Konzept des „imjaslavie“ erarbeitet. Zusätzlich referiert Bogen ausgewählte Positionen der russischen wie anglophonen Sekundärliteratur zu Mandel'štam. Die deutschsprachige wissenschaftliche Erschließung von Mandel'štams Werk etwa von Ralph Dutli wird von Vf. dagegen nur in relativ knapp bemessener Auswahl zur Kenntnis genommen.

Problematisch scheint der am Ende des ersten Teils umrissene methodische Zugang zu den Primärtexten, der sich vorab eingenommenen theoretischen Positionen zugunsten einer ,intuitiven Analyse“ (32) versagt, die im Akt der Lektüre der Bewegung einer (zuvor freilich nur ungenügend definierten) Substanz auf den verschiedenen Ebenen des Textes nachspüren soll. Bogen zählt abschließend zwar die ihren Zugang prägenden zentralen Fragestellungen taxativ und insgesamt konzise auf, dennoch mutet die Absage an jegliche Art von methodologischen Prämissen doch etwas seltsam an und wird von Vf. in den darauffolgenden Einzelanalysen de facto nicht wirklich durchgehalten: In Bogens auf Oppositionen wie etwa von Gesagtem und Ungesagtem und auf der Überschreitung von Grenzen aufruhender Argumentation schimmert 
nämlich erkennbar das semiotische Modell Jurij Lotmans durch. Der von Vf. ins Treffen geführte intuitive Zugang war offenbar ebenfalls für die Zusammenstellung des Textkorpus verantwortlich - während die Berücksichtigung von Mandel'štams frühem Gedicht Silentium als Gegenpol zum Spätwerk noch ausargumentiert wird, findet sich für die Auswahl der späten Gedichte keine Begründung mehr angegeben.

Teil zwei der Studie versammelt dann zehn Einzelanalysen, die mit den Gedichten Silentium (1910), Solominka (1916) und Komu zima - arak... (1922) gleich drei Texte umfassen, die definitiv nicht dem Spätwerk Osip Mandel'štams zuzurechnen sind (insbesondere das intertextuell auf Fedor Tjutčev verweisende Gedicht Silentium wurde in der Sekundärliteratur aufgrund seiner Motivik im Zeichen des Übergangs vom Symbolismus zum Akmeismus gedeutet). Die nachfolgenden sieben Gedichte dagegen stehen im Kontext von Mandel'štams „Voronežer Heften“ und repräsentieren von daher eindeutig das Spätwerk des Dichters (soweit bei Mandel'štam überhaupt von einem solchen zu sprechen ist). Es handelt sich dabei im Einzelnen um folgende Texte, die chronologisch von Anfang Dezember 1936 bis zum 7. April 1937 reichen und auch in dieser Reihenfolge analysiert werden: Ne u menja, ne u tebja - u nich..., Ottogo vse neudači..., Čto delat' nam s ubitost'ju ravnin..., das auf Leonardo da Vincis Abendmahl verweisende Nebo večeri v stenu vljubilos'..., Možet byt', èto točka bezumija..., O, kak $\check{z}$ e ja choču... und schließlich das nochmals die griechische Kultur aufrufende Flejty grečeskoj tèta i jota...

Über diese lyrischen Texte spannt Bogen ein Analyseraster, das im Wesentlichen die Positionen des lyrischen Subjekts gegenüber einem potentiellen lyrischen Du sowie der Objektwelt des Gedichts abgleicht und das die Kategorien Zeit und Raum ins Zentrum rückt. Besondere Intensität und Plausibilität gewinnt der so gewählte Zugang immer dann, wenn er sich stärker auf die Linearität des lyrischen Textes einlässt und dessen Sequenzen (Strophe, Zeile) schrittweise genauer auf das wechselseitige Interferieren von Phonetik, Metrik und Semantik und deren mögliches Auseinanderdriften hin abgleicht. Hier eröffnet Vf. tatsächlich analytische Zugänge, die ein neues und differenzierteres Verständnis der untersuchten Gedichte Osip Mandel'štams ermöglichen. Als wesentliche Prämisse dieses Vorgehens firmiert freilich eine fast durchgehend auf den einzelnen Text hin fokussierte und von daher, geschlossene Analyse. Sie öffnet sich nur in wenigen Fällen den für Mandel'štams Poetik essentiellen intertextuellen und -kulturellen Querverweisen (etwa den Anspielungen auf die Figur des Odysseus in Komu zima - arak...) und verweigert sich einer genaueren biographischen Kontextualisierung der untersuchten Gedichte.

Diese primär auf den Einzeltext hin gerichtete Fokussierung, die von Bogen eindeutig bevorzugt wird, scheint gleichermaßen legitim wie stimmig. Freilich versagt sie sich gerade auf der semantischen Ebene der Gedichte der Möglichkeit, die 
untersuchten lyrischen Motive durch den Abgleich mit anderen Texten des Autors gerade in deren wechselndem Bedeutungsgehalt zu bestimmen (konsequenterweise scheint die von Demetrius J. Koubourlis bereits 1974 edierte Konkordanz zu den Gedichten Mandel'štams, die einen derartigen Abgleich beträchtlich erleichtert, nicht im Literaturverzeichnis der Arbeit auf). Auch zu dem in Mandel'štams Essays beginnend mit $O$ sobesednike durchgehend postulierten, dialogischen Interagieren der Kulturen steht das Vorgehen, zu dem sich Vf. entschlossen hat, in deutlichem Widerspruch. Es bewährt sich hingegen immer dort, wo die textinternen Bezüge und Querverweise des untersuchten Gedichtes besonders dicht gefügt sind und die für Mandel'štam grundlegenden textexternen Verweise von daher ein Stück weit in den Hintergrund treten, wie etwa bei $O$, kak že ja choču... Hier werden die Relationen zwischen dem gegenüber anderen lyrischen Texten Mandel'štams deutlich reduzierten Instanzen von „Ich“, „Du“, „Er“ und dem Motiv des Lichtes sowie den akustischen Emanationen von Flüstern (,šepot“) und Lallen („lepet“) nachdrücklich und intensiv zur Darstellung gebracht (es ist wohl kein Zufall, dass Paul Celan gerade dieses sich dem Absoluten annähernde Gedicht als eines der wenigen aus Mandel'štams Spätwerk ins Deutsche übertragen hat).

Als möglicher Preis, der für die Wahl einer intuitiven (statt einer methodologisch abgesicherten und von daher konsequent umgesetzten) Form der Analyse zu entrichten ist, erscheinen die offensichtlichen Probleme, die teilweise durchaus überzeugenden Einzelanalysen der Gedichte abschließend dann auch zu einer stimmigen Synthese zusammenzuführen: Der elfte und letzte Unterabschnitt von Teil zwei der Studie verspricht über seinen Titel Tekst kak model': obobščajuščij analiz zwar genau dieses. De facto zerfällt er aber analog zu den zehn zuvor untersuchten Gedichten in ebenfalls zehn je rund eine Seite knappen Einzeldarstellungen wie etwa das „Modell des Lichtes" zu dem obenerwähnten Gedicht $O$, kak že ja choču... Diese Medaillons lassen sich freilich kaum zu einem größeren gemeinsamen Ganzen zusammenfügen und stehen in letzter Konsequenz ähnlich lose verbunden hintereinander wie zuvor die Einzelanalysen der Gedichte. Analoges gilt auch für den dritten und letzten Teil der Studie, der auf gut fünf Seiten den Anspruch erhebt, Aussagen über die Natur des Textes zu treffen (vgl. den Titel Priroda teksta), diesen Anspruch freilich nur bedingt einlösen kann. Bogen postuliert hier eine prinzipielle „Unverständlichkeit“ der späten Texte Mandel'štams (und kommt damit Paul de Mans These von der „Unlesbarkeit“ des Textes nahe), sofern der Leser sich diesen Texten auf der Ebene der Semantik anzunähern versucht. Dieses Postulat scheint vor dem Hintergrund der vorangegangenen Darstellung durchaus schlüssig, die Gleichsetzung von Text und Substanz („Tekst kak substancija“) hingegen gewinnt ungeachtet des Umstandes, dass sie den gesamten Band hindurch ins Spiel gebracht wird, nicht zuletzt aufgrund der Komplexität des philosophischen Begriffs „Substanz" keine klaren Konturen. 
Insgesamt hinterlässt Svetlana Bogens Studie (deren Anmerkungsapparat passagenweise etwas nachlässig gearbeitet ist) einen ambivalenten Eindruck: Das ambitionierte Vorhaben, sich Mandel'štams späten Gedichten im Zeichen des Performativen anzunähern, eröffnet ohne jeden Zweifel eine Vielzahl an Perspektiven, die ein intertextuell ausgerichteter Zugang so nicht zu bieten vermag und die in den Einzelanalysen zum Teil auch eingelöst werden. Dessen ungeachtet hätte eine stringenter gehaltene Darstellung dem gewählten Ansatz wohl ein deutlich höheres Maß an Überzeugungskraft verliehen.

Stefan Simonek

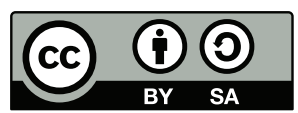

This work can be used in accordance with the Creative Commons BY-SA 4.0 International license terms and conditions (<https://creativecommons.org/licenses/by-sa/4.0/legalcode>). This does not apply to works or elements (such as images or photographs) that are used in the work under a contractual license or exception or limitation to relevant rights.

\section{K výzkumu etnických stereotypů ve střední Evropě}

ZELENKA, M. - TKÁČ-ZABÁKOVÁ, L. (eds): Imagológia ako výskum obrazov kultúry: $K$ reflexii etnických stereotypov krajín $V_{4}$. Nitra: Univerzita Konštantína Filozofa, 2018, 162 s. ISBN 978-80-558-1294-6.

Publikace je výstupem z vědecko-výzkumného projektu VEGA 1/0629/17 s názvem „Etnické stereotypy v literatúre krajín $\mathrm{V}_{4}$ “ a je vydávána „pri príležitosti 15. výročia založenia Fakulty stredoeurópskych štúdií Univerzity Konštantína Filozofa v Nitre". Jak čteme už v metodologicky koncipovaném Úvodu, přináší tato kolektivní monografie, na níž se podílelo patnáct badatelů ze zemí $\mathrm{V}_{4}$ (jádrem autorského kolektivu jsou členové špičkového badatelského týmu Stredoeurópske medziliterárne vzt’ahy při FSŠ UKF), „teoretické, literárnohistorické a kulturologické reflexie z oblasti, ktorá je tradične vymedzovaná ako špecifická disciplina porovnávacej literárnej vedy s náležitou metodológiou. “(S. 5.) Imagologie by podle editorů svazku měla být „chápaná ako spôsob medzikultúrnej, hermeneuticky orientovanej komunikácie, v ktorej analýza stereotypov nesmie slúžit $k$ vlastnej prezentácii a interpretácii „cudzieho“, ale $k$ jeho pochopeniu, porozumeniu či nastoleniu dialógu. “(Tamt.) Právě na tomto místě je nutno připomenout další důležitý fakt, nejen pro badatele, ale i studenty literární komparatistiky, že editoři „na záver zborníka pretláčajú slovenský preklad zásadnej štúdie jedného zo 